\title{
CDQ and IJEVG editors' joint statement on the third special international section
}

\author{
Jérôme Rossier · Jerry Trusty • \\ Donna E. Schultheiss • Raoul Van Esbroeck • \\ Spencer Niles
}

Published online: 26 February 2012

(C) Springer Science+Business Media B.V. 2012

The first special international issues of the Career Development Quarterly (CDQ) and the International Journal for Educational and Vocational Guidance (IJEVG) were published in 2005. These companion issues presented products from the first International Association for Educational and Vocational Guidance (IAEVG) and National Career Development Association (NCDA) symposium held in San Francisco in 2004. The CDQ and IJEVG issues included selected papers presented at the symposium and a summary of the results from the discussions. The CDQ and IJEVG issues, in essence, served as the symposium proceedings. Editors were Van Esbroeck, Herr and Savickas (2005) for CDQ and Savickas, Van Esbroeck, and Herr (2005) for IJEVG.

\section{J. Rossier $(\bowtie)$}

Institute of Psychology, University of Lausanne, Anthropole-3127, 1015 Lausanne, Switzerland e-mail: Jerome.Rossier@unil.ch

\section{J. Trusty}

College of Education, The Pennsylvania State University, 327 CEDAR Building,

University Park, PA 16802, USA

e-mail: jgt3@psu.edu

\section{E. Schultheiss}

College of Education and Human Services, Cleveland State University, 2121 Euclid Ave. JH 284,

Cleveland, $\mathrm{OH} 44115$, USA

e-mail: d.schultheiss@csuohio.edu

R. Van Esbroeck

Psychologie en Educatiewetenschappen, Vrije Universiteit Brussel, Pleinlaan 2,

1050 Brussel, Belgium

e-mail: Raoul.Van.Esbroeck@vub.ac.be

\section{S. Niles}

College of Education, The Pennsylvania State University, 125E CEDAR Building,

University Park, PA 16802, USA

e-mail: sgn3@psu.edu 
Inspired by successes from the first IAEVG-NCDA symposium, the boards of both associations considered organizing a second symposium. At the 2005 Society for Vocational Psychology (SVP) biennial conference held in Vancouver, Canada, the then presidents of NCDA, Janet Lenz, and SVP, David Blustein and Paul Gore, together with the IAEVG chair of the first joint symposium, Raoul Van Esbroeck, discussed a new joint symposium sponsored by all three organizations. The boards of the three organizations appointed a Joint Planning Committee. The Planning Committee received strong support from Italian colleagues of the University of Padova under the leadership of Salvatore Soresi and Laura Nota, who chaired the Local Organizing Committee. Together, these groups organized the 2007 IAEVG-SVP-NCDA international symposium on Vocational Psychology and Career Guidance Practice: An International Partnership. This symposium was held in September, 2007, in Padova, Italy, alongside the annual IAEVG international conference.

The Planning Committee used a format for the proceedings similar to that of the 2004 symposium, and again proposed the publication of companion issues of CDQ and the IJEVG. The boards of both journals/organizations supported this option and appointed a guest editorial team representing the three collaborating associations, including Jerry Trusty (NCDA), Raoul Van Esbroeck (IAEVG), and Paul Gore (SVP). These editors published companion CDQ and IJEVG issues (CDQ, Trusty, Van Esbroeck, \& Gore, 2009; IJEVG, Van Esbroeck, Van Esbroeck, Trusty, \& Gore, 2009). The Career Development Quarterly presented the keynote contribution, the outcomes of the activities in the discussion groups, and the general conclusions; whereas the International Journal for Educational and Vocational Guidance published a selection of papers presented in these groups. Also, our Italian colleagues published a conference book on the IAEVG conference and included a number of the symposium papers.

In 2009, leaders from SVP, NCDA, and IAEVG discussed the possibility of a third international symposium to be held in conjunction with the 2010 NCDA conference in San Francisco. The Planning Committee for this effort included Donna Schultheiss (SVP), Spencer Niles (NCDA), and Raoul Van Esbroeck (IAEVG). In organizing the third international symposium, the Planning Committee considered recurring themes from previous symposia, and emerging themes in international career development. The result was seven identified themes and seven corresponding groups to discuss issues and develop action plans.

At the 2010 NCDA-IAEVG-SVP international symposium, Building International Perspectives of Career Development, the Planning Committee and the editors of CDQ (Jerry Trusty) and IJEVG (Jérôme Rossier) planned for a third companion publication. The CDQ special issue includes articles from each of the seven groups at the symposium. It also includes introduction and summary articles by Jane Goodman. The IJEVG includes a special section of three selected articles. The first article entitled "An international discussion about cross-cultural career assessment," by Debra S. Osborn addresses a very important topic concerning techniques and assessments in the field, and she claims that international collaboration in developing new techniques, new assessments tools, and adapted ethical standards are important if our intention is to develop career assessment adapted to a plurality of cultural settings. More precisely, a multi-national approach when developing new 
techniques should be encouraged. Debra S. Osborn's contribution is certainly a very important one that illustrates very well the work done within the discussion group \#2. The second article entitled "Embracing and harnessing diversity in the US workforce: What have we learned," by Mark Pope presents a literature review about career counseling and cultural diversity that highlights 13 keys for increasing effective practice with clients belonging to minority groups. For example, we should all be aware of our biases, of our cultural identity and of the cultural identity of our clients, and develop a culturally sensitive attitude in order to understand the special issues our clients have to face, etc. All of these key issues are of prime importance for counselors working with diverse populations, which is more frequently the case for most counselors around the world these days. The question of the effectiveness of these 13 keys in cultures that are very different to those in north America remains to be seen. Several very interesting studies could be conducted to answer this very important question. Mark Pope's contribution illustrates that the issues discussion group \#4 discussed have several very important practical implications. Finally, the article entitled "Career learning and development: a social constructivist model for the 21st century," by Barbara Bassot emphasizes that contemporary rapid social changes constitute a challenge for our field because we have to develop new models in order to provide adapted services to our clients. Career construction, life designing, career adaptability, and career learning and development are all models that claim that peoples' subjective representations have to be taken into account using specific and adapted tools and techniques. The concept of career learning and development is presented using a bridge metaphor that implies that all forces and tensions are in equilibrium. Instability might lead to stability, but in some cases we also consider instability as a chance for development. Barbara Bassot's contribution is certainly a nice example of the presentations given by the participants of discussion group \#6. However, this model should be further developed in order to describe more precisely the specificities and similarities with other constructivist, integrative, or pluralist models recently developed in our field.

We, the editors of CDQ and IJEVG hope that the products contained within the two journals are useful for career development professionals and clients-studentsworkers around the world. We thank the Symposium Planning Committee, the authors, symposium attendees, and publication production staffs for their contributions to this effort.

\section{References}

Savickas, M. L., Van Esbroeck, R., \& Herr, E. L. (2005). Global perspectives on vocational guidance [Special Issue]. International Journal for Educational and Vocational Guidance, 5(2).

Trusty, J., Van Esbroeck, R., \& Gore, P. A., Jr. (2009). Vocational psychology and career guidance practice: An international partnership [Special Issue]. The Career Development Quarterly, 57(4).

Van Esbroeck, R., Herr, E. L., \& Savickas, M. L. (2005). Global perspectives on vocational guidance [Special Issue]. The Career Development Quarterly, 54(1).

Van Esbroeck, R., Trusty, J., \& Gore, P. A., Jr. (2009). Vocational psychology and career guidance practice: An international partnership [Special Issue]. International Journal for Educational and Vocational Guidance, 9(2). 